\title{
ÁLCOOL EM GEL PARA ASSEPSIA DAS MÃOS - FORMULAÇÃO ADEQUADA E EFICIÊNCIA GARANTIDA EM MEIO À PANDEMIA DA COVID-19
}

\author{
Kleber Queiroz Ferreira ${ }^{a}$, Isabel C. Rigolia, Marcus V. S. da Silva ${ }^{\mathrm{b}}$, Alexandre de Freitas Espeleta e Zênis Novais da \\ Rocha $^{\mathrm{a}, *, \text { (i) }}$ \\ anstituto de Química, Universidade Federal da Bahia, Campus Universitário de Ondina, 40170-290 Salvador - BA, Brasil \\ 'Instituto de Física, Universidade Federal da Bahia, Campus Universitário de Ondina, 40170-290 Salvador - BA, Brasil \\ 'Universidade Estadual de Feira de Santana, 44036-900 Novo Horizonte - BA, Brasil
}

Recebido em 14/06/2021; aceito em 10/09/2021; publicado na web em 13/10/2021

\begin{abstract}
ALCOHOL GEL FOR ASEPSY OF THE HANDS - PROPER FORMULATION AND GUARANTEED EFFICIENCY AMID THE PANDEMIC OF COVID-19. The use of hand antiseptics became widespread as a routine in the fight against COVID-19. In the market, the availability and purchase of substandard antiseptics create a permanent concern with safety, even after a pandemic. Therefore, the development of easy-to-deploy analytical methods for the quality control of alcohol-based hand antiseptics is needed. In this work, to determine the ethanol content in alcohol gel the use of refractometry and alcohol oxidation method by dichromate accompanied by UV-Vis spectroscopy were applied. The results indicated that 19 brands (out of the 70 evaluated) (27.1\%) had levels of ethyl alcohol below the recommended level $(68.25 \%)$, therefore, they are ineffective for hand asepsis. For the quality control of hand antiseptics, refractometry and the oxidation-reduction reaction are complementary analytical methodologies. As a quick, inexpensive screening method, refractometry provides a more suitable technique. However, the interference of emollients may affect the accuracy of the ethanol content determination. Therefore, applying the ethanol oxidation method coupled with electronic spectroscopy offers a simple and broadly accessible method to confirm the ethanol content in alcohol-based hand antiseptics. In addition to developing quality control protocols, is also described the 3.5-ton production of alcohol gel at the Federal University of Bahia.
\end{abstract}

Keywords: alcohol gel; COVID-19; hand sanitizers; disinfection.

\section{INTRODUÇÃO}

Como medida importante para tentar mitigar o crescimento da curva de transmissão pelo novo coronavírus (SARS-CoV-2) é destacada a utilização de álcool em gel para assepsia das mãos, preocupação expressada em diferentes publicações. ${ }^{1-4}$

A Organização Mundial de Saúde (OMS) em 11 de março de 2020 classificou a COVID-19 como uma pandemia o que acarretou um aumento da procura pelo álcool em gel e resultou no desabastecimento desse produto no mercado. Quando possível encontrar o valor era muito alto e, por consequência, os fornecedores tiveram dificuldades para atenderem as solicitações das unidades de saúde e do comércio.

Hoje, em diversos estabelecimentos comerciais pode ser encontrada uma variedade de formulação de álcool em gel para higienização das mãos. No início da pandemia, em função da alta demanda do produto, houve em todos os países a escassez do agente gelificante carbopol 980 (polímero acrílico), o qual é usado para produzir o álcool em gel. Tal fato resultou em um aumento de produtos de qualidade questionável que podem não cumprir sua função antisséptica, o que torna fundamental o debate sobre a qualidade do produto ofertado.

A Administração de Alimentos e Medicamentos dos Estados Unidos da América (US FDA), Centros de Controle e Prevenção de Doenças (CDC) e pela OMS indicam que concentrações de etanol de $60 \%$ a $95 \%$ (v/v) em volume são consideradas eficientes para desinfecção das mãos inclusive para o novo coronavírus. Porém, estudos de alguns pesquisadores ${ }^{5,6}$ levaram a conclusão que o aumento da concentração do álcool para esfregaço das mãos resulta na redução do tempo de contato para obter uma atividade bactericida adequada.

*e-mail: zenis@ufba.br
Recentemente, Kampf e colaboradores ${ }^{3}$ relataram que a inativação do coronavírus em determinadas superfícies, como metais, vidros e outras, é efetiva com uso de sanitizantes contendo o teor de álcool etílico de $62-71 \%$ (teor não especificado se $\mathrm{m} / \mathrm{m}$ ou v/v).

No sentido de orientar e destacar os aspectos críticos da produção e preparações antissépticas alcoólicas, com base nas diretrizes do Formulário Nacional da Farmacopeia Brasileira ${ }^{7}$ e no Guia da OMS ${ }^{4}$ em março de 2020, a Anvisa lançou uma publicação de título "Orientações Gerais para a Produção de Formulações Antissépticas. ${ }^{8}$

$\mathrm{Na}$ resolução da diretoria colegiada (RDC) $\mathrm{n}^{\circ} 422$ de 16 de setembro de $2020,{ }^{9}$ a qual altera a RDC de 19 de março de $2020^{10}$ - Ministério da Saúde/Agência Nacional de Vigilância Sanitária, consta no artigo $4^{\circ}$ parágrafo 2 - "Os cosméticos indicados para serviços de saúde, exceto na forma líquida, também devem respeitar o teor mínimo de $68,25 \%$ (m/m)". No artigo $4^{\circ}$ parágrafo 1 cita - “a concentração de álcool no produto cosmético não poderá ter valor que represente variação superior a $10 \%$ (dez por cento) em relação à concentração do álcool declarada na rotulagem do produto em 'INPM $(\% \mathrm{~m} / \mathrm{m}) "$.

No artigo $5^{\circ}$ parágrafo único da RDC 422 consta - "A fabricação dos antissépticos oficinais deve seguir as diretrizes da $2^{\mathrm{a}}$ Edição, Revisão 2, do Formulário Nacional da Farmacopeia Brasileira". ${ }^{7} \mathrm{Na}$ formulação do álcool em gel os componentes essenciais são: álcool etílico água, emoliente (cuja função é hidratar as mãos), espessante (matéria prima que resulta na viscosidade do produto) e corretivo do $\mathrm{pH}^{1}$. No formulário - página 60 , consta como espessante o carbopol 980 e correção do $\mathrm{pH}$ na faixa de 5-77 para esse insumo.

A adulteração de antissépticos para as mãos à base de etanol como ingrediente ativo é uma preocupação cada vez maior no mercado brasileiro. Em função do grande apelo no sentido de avaliar a qualidade de antissépticos à base de álcool etílico, recentemente, 
Fonseca Jr e colaboradores ${ }^{11}$ e Pasquini e colaboradores ${ }^{12}$ usaram a espectroscopia na região do infravermelho próximo associada à quimiometria para determinação do teor do álcool etílico em diferentes marcas do álcool em gel. Fonseca Jr. e colaboradores ${ }^{11}$ destacaram que 34 marcas de álcool em gel foram avaliadas das quais somente 7 apresentaram o teor de álcool de $70 \%(\mathrm{~m} / \mathrm{m})$ ou superior. A baixa porcentagem de marcas de álcool em gel adequados para assepsia das mãos em meio à pandemia retrata a necessidade de uma fiscalização efetiva e contínua.

Tendo em vista a necessidade do controle da qualidade do álcool em gel para inativar SARS-CoV-2, além de desenvolver um método eficiente e barato para a obtenção do produto que atenda esse apelo, este trabalho tem como objetivos: i - aplicar duas metodologias - refratometria e reação de oxirredução - na determinação do teor de álcool etílico no álcool em gel para assepsia das mãos. ii descrever o processo de produção de álcool em gel no Instituto de Química-UFBA.

Trabalhos realizados no IQ-UFBA indicaram, como resultado da investigação, que $27,1 \%$ das 70 marcas analisadas tem teor de álcool etílico abaixo do limite inferior $68,25^{\circ}$ INPM. ${ }^{9}$ Tais resultados reforçam a necessidade de que medidas sejam tomadas, como uma fiscalização efetiva, a fim de evitar que os consumidores façam uso de produtos ineficientes para higienização das mãos. A supervisão rigorosa desses materiais disponíveis no mercado é essencial, visto que o cidadão está limitado apenas às informações apresentadas nos rótulos das embalagens e em algumas propriedades organolépticas, tais como transparência, cor e homogeneidade, que apresentem uma boa aparência, no entanto, tais parâmetros não são garantia da função antisséptica do produto, e não validam sua efetividade em meio à pandemia e/ou pós pandemia

\section{PARTE EXPERIMENTAL}

\section{Reagentes}

Álcool etílico (96\% v/v) (CANEX BIOENERGIA LTDA); glicerina - bidestilada ((TECOVEL - grau cosmético), dipropilenoglicol (TECOVEL - grau cosmético), colágeno hidrolisado em pó (GELITA - grau cosmético), hidroxometiletilcelulose (HEMC) (COMBIZELL LH 70 MR) (TIANPU CHEMICALS COMPANY LIMITED), trietanolamina (TECOVEL), dicromato de potássio (RIEDEL), ácido sulfúrico (FISHER CHEMICAL) e água bidestilada.

\section{Equipamentos}

Refratômetros portátil (ATC- 0-32 Brix) e de bancada (N/S20186101- IONLAB Equipamentos) foram usados, após calibração com água bidestilada, para se obter os valores de índice de refração (IR) e teor de Brix ( $\left.{ }^{0} \mathrm{BX}\right)$. Alcoolômetro (PYROMEDPY5683) para certificar o teor de álcool nos diferentes lotes. Ebulidor gigante $-2000 \mathrm{~W}$ e $220 \mathrm{~V}$ (CHERUBINO).

Os espectros na região do ultravioleta visível (UV-Vis) foram registrados no aparelho CARY 50 (VARIAN) - modelo 1002MO, na faixa 200-800 nm. Para as leituras as soluções foram colocadas em cela de quartzo de caminho ótico de $1 \mathrm{~cm}$.

As medidas de $\mathrm{pH}$ foram realizadas em pHmetro HANNA Instruments modelo HI 9321, calibrado usando soluções tampão de $\mathrm{pH} 4,65$ e 6,86 à temperatura de $25^{\circ} \mathrm{C}$.

\section{Produção do álcool em gel}

O álcool em gel foi preparado em tanques de aço inoxidável com capacidade de 25 L e 45 L. Foram preparados lotes de no máximo
$18 \mathrm{~kg}$ e $35 \mathrm{~kg}$ por vez, para uma melhor homogeneização dos insumos. A produção teve início em 01/04/2020 e em 20 de dezembro de 2020 alcançou 3,5 toneladas de álcool em gel.

Nos tanques foram aquecidos com uso de um ebulidor até $70^{\circ} \mathrm{C}$ (o aquecimento é opcional) - a massa de água bidestilada correspondente à $25 \%$ do montante do álcool em gel a ser preparado, junto com $0,6 \%$ em massa de glicerina bidestilada e $0,55 \%$ de dipropilenoglicol, em seguida foi acrescentado o espessante, COMBIZELL LH-70 MR com teor de 0,55\% sob agitação constante (1600-1700 rpm). Para a mistura/agitação foram utilizados agitadores mecânicos, com hélice misturadora tipo Cowles. Após 5 minutos, foi adicionada uma solução aquosa ( $25 \mathrm{~mL}$ ) contendo $0,055 \%$ do colágeno. A agitação foi mantida e a temperatura foi monitorada em $50{ }^{\circ} \mathrm{C}$ e, assim, a adição da massa do álcool etílico foi executada. Em intervalos curtos, foi usada uma espátula de aço inox para auxiliar na homogeneização do sistema e a rotação do agitador mecânico foi aumentada para $2100 \mathrm{rpm}$ por mais 30-40 minutos, seguida do envase do produto em frascos com capacidade de $500 \mathrm{~mL}$ e $100 \mathrm{~mL}$.

É importante destacar que as pessoas envolvidas na produção seguiram as recomendações para atender as boas práticas farmacêuticas.

\section{Avaliação do teor de álcool etílico em diferentes marcas de álcool em gel}

\section{Curvas de referência para as análises de refratometria}

No sentido de avaliar o teor do álcool etílico em diferentes marcas de álcool em gel para higienização das mãos e de sanitizantes, neste trabalho, inicialmente foram obtidos os valores ${ }^{\circ} \mathrm{BX}$ (I) e o IR (II), com uso de refratômetros portátil (I) e de bancada (I e II), para as soluções binárias - água e etanol (30-95\% em massa do álcool) e os valores foram tomados como referência para determinar a porcentagem de etanol. As leituras foram efetuadas após a calibração dos refratômetros com água bidestilada. O Brix é uma medida do teor de sólidos solúveis em uma solução de sacarose, muito utilizado em indústrias de alimentos e tem relação com o índice de refração. Deste modo, é possível obter, com uso do refratômetro de bancada, as medidas do ${ }^{0} \mathrm{Bx}$ e IR. A correlação matemática entre os mesmos (Figura 1S) permite, com uso do refratômetro portátil, que fornece o ${ }^{0} \mathrm{Bx}$, obter o IR para as diferentes marcas de álcool em gel, com aplicação da relação matemática apresentada na Equação 1.

$$
\begin{gathered}
Y=-816,43+613,39 X \\
\left(Y={ }^{0} \mathrm{BX} \text { e } X=\mathrm{IR}\right)
\end{gathered}
$$

Na Tabela 1 estão apresentados os valores de ${ }^{0} \mathrm{BX}$ e IR para as misturas binárias - água-álcool etílico.

As curvas que ilustram a correlação entre os teores de Brix em relação a porcentagem em massa de álcool nas diferentes misturas nos dois refratômetros foram avaliadas e estão representadas nas Figuras $2 \mathrm{~S}$ e $3 \mathrm{~S}$. O mesmo estudo foi realizado tomando como base o índice de refração e as curvas podem ser consultadas nas Figuras $4 \mathrm{~S}$ e 5S. As curvas de ajuste dos dados resultaram nos parâmetros apresentados na Tabela 1S. Das curvas de ajustes encontradas para ambos os instrumentos, foi verificado que independente do refratômetro os ajustes conseguem seguir de maneira eficiente todos os conjuntos de pontos experimentais.

Um tratamento matemático das curvas apresentadas para teor de Brix e índice de refração versus o teor de álcool foram efetuados para obter o teor de álcool etílico nas diferentes marcas de álcool líquido (sanitizantes) e álcool em gel (cosméticos). A expressão com ajuste mais adequado dos pontos experimentais é a função polinomial do segundo grau, ilustrado pela Equação 2. A variável Y representa ${ }^{\circ} \mathrm{BX}$ 
Tabela 1. Valores de correlação entre ${ }^{\circ} \mathrm{BX}$ e IR

\begin{tabular}{cccccc}
\hline \multirow{2}{*}{$\begin{array}{c}\text { Teor de } \\
\text { álcool }(\%)\end{array}$} & \multicolumn{2}{c}{ Portátil - calculado (IR) } & & \multicolumn{2}{c}{ Bancada } \\
\cline { 2 - 3 } \cline { 5 - 6 } (em massa) & ${ }^{\circ} \mathrm{BX}(\%)$ & IR & & ${ }^{\circ} \mathrm{BX}(\%)$ & IR \\
\hline 30 & 12,8 & 1,3521 & & 13,00 & 1,3525 \\
35 & 14,0 & 1,3541 & & 14,10 & 1,3542 \\
40 & 15,2 & 1,3560 & & 15,37 & 1,3565 \\
45 & 16,0 & 1,3573 & & 16,75 & 1,3580 \\
50 & 16,8 & 1,3586 & & 17,25 & 1,3595 \\
55 & 18,0 & 1,3605 & & 18,18 & 1,3608 \\
60 & 18,2 & 1,3609 & & 18,25 & 1,3615 \\
65 & 18,8 & 1,3619 & & 18,85 & 1,3620 \\
70 & 19,2 & 1,3625 & & 19,25 & 1,3626 \\
75 & 19,2 & 1,3625 & & 19,25 & 1,3626 \\
80 & 19,2 & 1,3625 & & 19,25 & 1,3626 \\
85 & 19,2 & 1,3625 & & 19,25 & 1,3626 \\
95 & 18,2 & 1,3609 & & 18,75 & 1,3615 \\
\hline
\end{tabular}

ou o índice de refração e X é o teor de álcool etílico e A, $B_{1}$ e $B_{2}$ são os parâmetros que estão indicados na Tabela 1S. Da Equação 2, que pode ser resolvida e resultar na Equação 3, é possível determinar o teor de álcool etílico no álcool em gel e em sanitizantes, para um dado valor de teor de Brix ou índice de refração. Uma planilha no programa Excel foi construída o que permite encontrar o teor de álcool para os casos nos quais os valores de índice de refração e teor de Brix estão dentro da curva de ajuste.

$$
\begin{gathered}
Y=A+B_{1} x+B_{2} x^{2} \\
x(y)=\frac{-B_{1} \pm \sqrt{B_{1}^{2}-4 \cdot B_{2}(A-(y))}}{2 \cdot B_{2}}
\end{gathered}
$$

Curvas de referência para as análises de oxirredução

O etanol pode ser oxidado, com o envolvimento de quatro elétrons e resultar ácido acético. $\mathrm{O}$ dicromato é um ânion inorgânico no qual o átomo de crômio se encontra com número de oxidação VI e com base no potencial padrão de redução $\left(1,33 \mathrm{~V}\right.$ vs EPH), ${ }^{13}$ afirma-se que é um oxidante relativamente forte. Os processos de redução e oxidação (eq. IS-r e IS-o) das espécies químicas estão representados no Esquema 1S. A reação global do processo químico, após balanço de massa e carga das semiequações, é representada pela equação I.

$2 \mathrm{Cr}_{2} \mathrm{O}_{7}{ }^{2-}{ }_{(\mathrm{aq})}+3 \mathrm{H}_{3} \mathrm{CCH}_{2} \mathrm{OH}+16 \mathrm{H}^{+}{ }_{(\mathrm{aq})} 4 \mathrm{Cr}^{3+}{ }_{(\mathrm{aq})}+3 \mathrm{H}_{3} \mathrm{CCOH}+$ $11 \mathrm{H}_{2} \mathrm{O}$

(Eq. I)

O produto da redução do dicromato resulta no crômio com número de oxidação III. Uma mistura de solução do dicromato com etanol, a depender da concentração do etanol, forma uma solução de coloração - amarelo esverdeada ou verde - amarelada ou verde azulada ou azulesverdeada ou azul. Um acompanhamento da alteração espectroscópica na região do ultravioleta - visível pode ser efetuado e assim obter informações do teor de álcool em uma dada amostra. Medidas cinéticas das reações de oxirredução confirmam que as velocidades dessas reações diminuem com o aumento do número de elétrons envolvidos, ${ }^{13}$ assim, essa reação entre dicromato com etanol, a qual envolve 4 elétrons para oxidar o álcool, é relativamente lenta. Além disso, as velocidades observáveis das reações são dependentes das concentrações dos reagentes e foi notado que para porcentagem mais baixa que $50 \%$ de etanol, tempos menores acarretaram erros nas medidas. Após vários testes, tanto da quantidade de matéria do dicromato como do tempo, foi verificado que nas curvas de referência também denominadas curvas padrão, com $30 \%$ em massa do álcool o ideal era mais tempo. Então, foi selecionado o tempo de 60 minutos, com a concentração de $0,2 \mathrm{~mol}$ $\mathrm{L}^{-1}$ do dicromato, como relatado a seguir, e usando a solução aquosa do álcool $70 \%(\mathrm{~m} / \mathrm{m})$ como referência.

A fim de construir as curvas de referência, a alteração espectroscópica foi avaliada em tempos diferentes e com volumes variados da solução de dicromato $0,2 \mathrm{~mol} \mathrm{~L}^{-1}$ para a porcentagem de álcool de $30-80 \%(\mathrm{~m} / \mathrm{m})$. Cada mistura foi repetida no mínimo por 3 vezes e com diferentes razões de quantidade de matéria dicromatoetanol. Entre as razões avaliadas a de variação mais sistemática nos valores relativos de absorvância, bem como, no perfil do espectro eletrônico foi de: $1000 \mu \mathrm{L}$ da solução de dicromato, o que equivale a uma quantidade de matéria de $2,0 \times 10^{-4} \mathrm{~mol} \mathrm{e} 450 \mu \mathrm{L}$ da solução de etanol, os quais foram adicionados em um balão volumétrico de $10 \mathrm{~mL}$ e o volume completado com solução aquosa de $\mathrm{H}_{2} \mathrm{SO}_{4}$ a $20 \%$ (v/v). A mistura foi transferida para um béquer e submetida a agitação magnética por 60 minutos. As soluções aquosas de etanol foram preparadas tendo como referência a solução aquosa com $70 \%(\mathrm{~m} / \mathrm{m})$ de álcool com $3,51 \times 10^{-4}$ mol de etanol, considerando a estequiometria da reação dicromato ( $2 \mathrm{~mol})$ - etanol ( $3 \mathrm{~mol})$, a quantidade de matéria do ânion foi um pouco superior à de álcool etílico.

As Figuras 1 e 2 ilustram os espectros eletrônicos registrados após 1 hora de reação entre solução de dicromato e solução binária água-álcool com teor de álcool de 40-65 (Figura 1) e 60-80\% (m/m) (Figura 2). Foi verificado um aumento da intensidade de absorvância em $582 \mathrm{~nm}$ que corresponde a formação do $\mathrm{Cr}^{3+}{ }_{(\text {aq) }}$ e decréscimo da absorvância ao redor de $440 \mathrm{~nm}$ relativo ao consumo do dicromato. Nas Figuras 1 e 2, foram observados pontos isosbésticos em $538 \mathrm{~nm}$ e $492 \mathrm{~nm}$, respectivamente. A alteração dos pontos isosbésticos ocorre

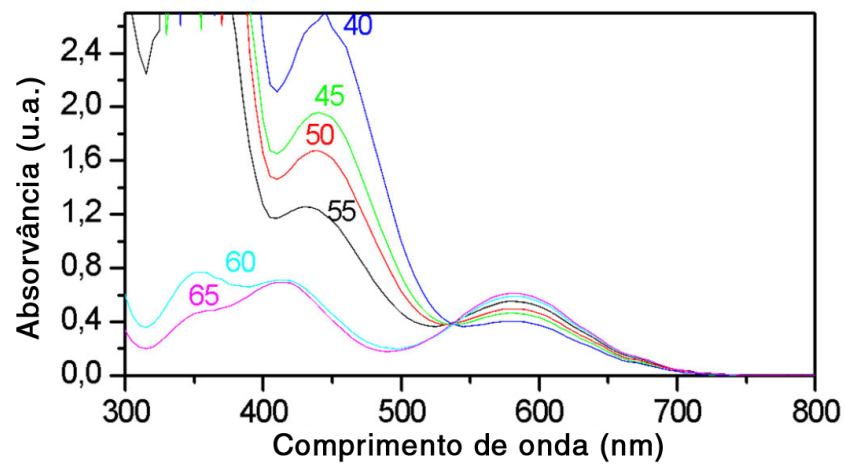

Figura 1. Espectros eletrônicos da mistura $\mathrm{Cr}_{2} \mathrm{O}_{7}^{2-}{ }_{(a q)}$ com mistura binária água-etanol (40-65\%) em meio ácido - após 1 hora de reação

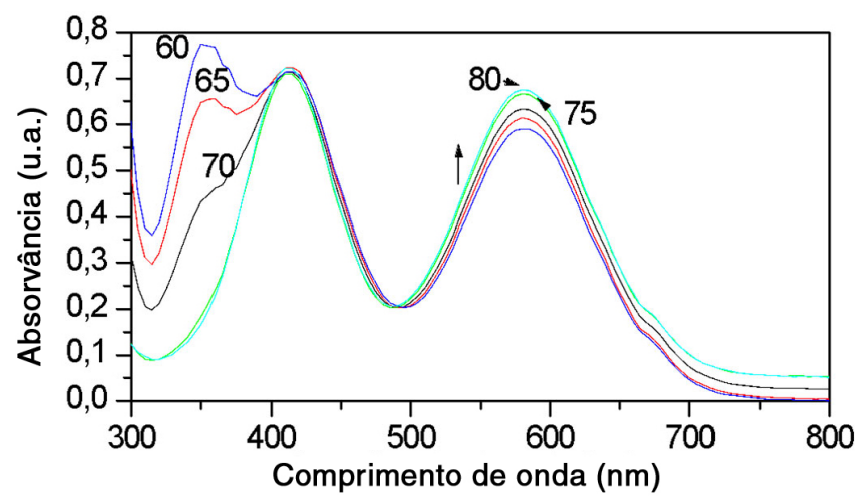

Figura 2. Espectros eletrônicos da mistura $\mathrm{Cr}_{2} \mathrm{O}_{7}^{2-}{ }_{(a q)}$ com mistura binária água-etanol (60-80\%) em meio ácido-após 1 hora de reação 
devido à mudança da razão de concentração entre $\mathrm{Cr}_{2} \mathrm{O}_{7}{ }^{2-}$ e $\mathrm{Cr}(\mathrm{III})$ (produto da reação), o que resulta em perfis diferentes dos espectros eletrônicos, ratificados ao comparar as curvas das Figuras 1 e 2.

Uma análise da absorvância medida em $582 \mathrm{~nm}$ em função do teor de álcool na mistura binária foi efetuada após correção do perfil dos espectros eletrônicos tomando como base em cada segmento a linha base para a mistura com menor porcentagem do álcool. Foram verificados dois segmentos, com correlação linear, que resulta nas curvas indicadas nas Figuras $6 \mathrm{~S}$ e 7S. O tratamento matemático das curvas resultou nas equações 4 e 5 .

$$
\begin{gathered}
y=-0,00455+0,0104 x \\
y=0,3194+0,00455 x
\end{gathered}
$$

Para os estudos nas diferentes marcas de álcool em gel, foi utilizada como referência a massa da solução hidroalcoólica $70 \%(\mathrm{~m} / \mathrm{m})$, usada para a construção das curvas de referência. As soluções aquosas do álcool em gel foram preparadas após determinar a massa da parte líquida do álcool em gel. Um tratamento térmico de uma massa conhecida, do álcool em gel, foi executado e assim pela diferença entre massa inicial do álcool em gel e massa seca foi possível ter conhecimento da massa necessária do álcool em gel para preparar a solução estoque. A referida massa foi solubilizada em água bidestilada e transferida para um balão volumétrico de $5 \mathrm{~mL}$ sendo essa a solução usada para determinar o teor do álcool etílico. Cada análise foi efetuada no mínimo 3 vezes em função das peculiaridades destacadas no item resultados e discussão das diferentes marcas e lotes. Com uso do valor da média de absorvância em $582 \mathrm{~nm}$ para cada amostra de álcool em gel e/ou por meio da comparação do perfil dos espectros eletrônicos, foi possível determinar o teor de álcool etílico nas diferentes marcas do álcool em gel.

Experimentos foram executados no sentido de avaliar se os componentes como glicerina e dipropilenoglicol, presentes em várias marcas de álcool em gel, mostram interferência nas análises. Soluções aquosas contendo $10 \%$ de glicerina (I) $10 \%$ de dipropilenoglicol (II), foram usadas para retirada de uma alíquota, com massa similar à usada nas análises do álcool em gel, certamente superiores àquelas encontradas em qualquer marca de álcool em gel, e misturadas com dicromato em seguida submetida a agitação por 60 minutos.

\section{RESULTADOS E DISCUSSÃO}

\section{Produção do álcool em gel no Instituto de Química (IQ) da UFBA e distribuição}

Segundo as informações reportadas no Formulário Nacional da Farmacopeia Brasileira o álcool em gel deve ser preparado com teor de $70 \%(\mathrm{~m} / \mathrm{m})\left(70{ }^{\circ} \mathrm{INPM}\right)$ ou $77 \%(\mathrm{v} / \mathrm{v})\left({ }^{\circ} \mathrm{GL}\right) .{ }^{7}$ No procedimento é recomendado como espessante o polímero carbômero $980^{7}$, no entanto, outros espessantes podem ser usados como substituintes deste insumo, medida que foi tomada no início da pandemia, em função da escassez e alto preço dos carbômeros. ${ }^{1}$ No artigo $5^{0}$ parágrafo único da RDC N 350 , de 19 de março de 2020 consta - "Na ausência de veículos, excipientes ou substâncias adjuvantes preconizadas pelo Formulário Nacional, é permitido à empresa a substituição por insumos que tenham a mesma função farmacotécnica e garantam a mesma eficácia e estabilidade ao produto". ${ }^{10}$

Neste trabalho, foram efetuados vários estudos na bancada a fim de buscar um espessante que pudesse suprir a falta de carbopol. Entre as diferentes tentativas foi possível avaliar o derivado de celulose nominado de COMBIZELL LH $70 \mathrm{MR}$, cuja viscosidade é dada pelo polímero HEMC. A produção no IQ da UFBA utilizou para a composição do álcool em gel esse espessante na porcentagem de
0,55\% acrescido de colágeno hidrolisado em uma concentração 10 vezes menor, ambos graus cosméticos, que resultou em um produto de ótima transparência, consistência, muito hidratante, e o mais importante, com teor de álcool de 70 `INPM. A estabilização do gel na mistura etanol-água com os demais componentes citados na parte experimental é resultante das ligações de hidrogênio (Figura 8S). Isso acontece, pois o COMBIZELL LH 70 MR é um espessante celulósico hidrofílico o que contribuiu para ser solúvel em água fria ou quente. $\mathrm{O}$ $\mathrm{pH}$ do produto foi corrigido com baixa quantidade de trietanolamina para alcançar o pH de 6,7 e o álcool gel chegou à uma viscosidade ideal que associada a presença de colágeno hidrolisado resultou em um produto que proporciona uma maior maciez nas mãos.

Na Tabela 2S são mostrados os insumos usados para a formulação do álcool em gel produzido no IQ-UFBA e o custo para a produção de $10 \mathrm{~kg}$ do produto. Os dados ilustram um gasto relativamente baixo para a obtenção do álcool em gel, o que mostrou a viabilidade da produção a fim de atender profissionais da área de saúde (hospitais e unidades de pronto atendimento) e profissionais terceirizados do Campus Universitário - Ondina da UFBA. Além disso, tem ocorrido com frequência a entrega do produto para a polícia militar - Salvador. A produção de álcool 70 INPM em gel para doação está autorizada pela Anvisa nos termos da RDC 350/2020 (DOU - 20/03/2020) ${ }^{10} \mathrm{e}$ especificada pela nota técnica número $2 / 2020$. Entre outras normas, a legislação estabelece a necessidade de um profissional devidamente habilitado e registrado no Conselho Regional de Química como responsável técnico.

\section{Análise do álcool em gel para assepsia das mãos}

\section{Propriedades organolépticas}

As propriedades organolépticas citadas na Tabela $3 \mathrm{~S}$ permitiram uma avaliação rápida de alguns aspectos das marcas analisadas. É importante destacar que medidas sejam tomadas a fim de evitar que os consumidores façam uso de produtos antissépticos para as mãos que, embora, apresentem uma boa aparência não garante a assepsia necessária e, portanto, não sejam efetivos para o uso em meio à pandemia em função de teor de álcool etílico inadequado. No máximo, o que os inúmeros consumidores podem avaliar ao fazerem uso do álcool em gel são os aspectos citados na Tabela 3S. Em diferentes locais nos quais a aquisição de álcool em gel foi efetuada não foi incomum ouvir de atendentes - "essa marca é muito boa", sem dúvida a afirmação foi pautada na aparência e/ou sensação nas mãos.

\section{Análise do teor de álcool etílico no álcool em gel e líquido - Refra- tometria}

Informações de misturas líquidas binárias podem ser obtidas com aplicação do estudo de refratometria. Em alguns processos industriais, tais como produção de bebidas, fármacos, alimentos, cosméticos e outros, a técnica de refratometria é aplicada a fim de buscar informações dos valores índice de refração os quais se encontram diretamente associados às alterações da concentração e composição das soluções e misturas de solventes. ${ }^{14,15}$

No sentido de avaliar o teor do álcool etílico em diferentes marcas antissépticos para as mãos e sanitizantes à base de etanol, neste trabalho, inicialmente foram obtidos os valores dos teores de Brix (I) e o índices de refração (II), com uso de refratômetros portátil (I) e de bancada (I e II), para as soluções binárias formadas por água e etanol (30-95\% em massa do álcool) (Tabela 1) e os valores foram tomados como referência para determinar a porcentagem do álcool etílico.

Estudo da literatura para mistura binária etanol - água ${ }^{15}$ mostra que os valores dos teores de Brix e índices de refração aumentam até uma determinada fração em quantidade de matéria, atingindo o valor máximo em $70 \%(\mathrm{~m} / \mathrm{m})$ de álcool e $30 \%(\mathrm{~m} / \mathrm{m})$ de água, fato 
que é resultante das interações de hidrogênio que são estabelecidas entre as moléculas de água e de álcool.

A avaliação da porcentagem do álcool etílico em sanitizantes, os quais contém a mistura binária água-álcool, com uso de refratômetros portátil e bancada resultaram nos dados indicados na Tabela 4S. Das 10 marcas de sanitizantes avaliadas as de código AL-9 e AL-10 apresentaram teores de álcool etílico, em massa, abaixo de $70 \%$, aspecto que não atende a recomendação da ANVISA. ${ }^{9}$

$\mathrm{Na}$ Tabela 2 são apresentados os dados usados para avaliar a eficácia de diferentes marcas de álcool em gel, para assepsia das mãos, comercializadas e produzidas no Munícipio de Salvador BA e também provenientes de diferentes estados. Estão reportados os valores de teores de álcool etílico para as medidas encontradas dentro do intervalo das curvas de ajuste, os quais foram determinados com uso da Equação 3, tendo como base de cálculo o teor de Brix e o índice de refração.

Ao avaliar os dados foi verificado que das 70 marcas e 83 amostras diferentes as análises efetuadas com aplicação da refratometria

Tabela 2. Dados do teor de Brix, índice de refração e pH para diferentes marcas de álcool em gel

\begin{tabular}{|c|c|c|c|c|c|c|}
\hline Código da Marca & BRIX $^{* *}$ & Índice de refração ${ }^{* * *}$ & $\begin{array}{c}\text { Teor de álcool - } \\
\text { estimado pelos } \\
\text { dados padrões }\end{array}$ & $\begin{array}{c}\text { Teor de álcool - } \\
\text { estimativa pela Equação } 3 \\
\text { (Uso do BX) / IR (B) }\end{array}$ & Validade & $\mathrm{pH}\left(\right.$ Faixa 5-7) ${ }^{7}$ \\
\hline AG-1a & $20,2(\mathrm{P})$ & 1,3642 & 70 & NA & $10 / 2021$ & \\
\hline$\overline{A G-1 b}$ & $\begin{array}{c}19,8(\mathrm{P}) \\
20,00(\mathrm{~B}) \\
\end{array}$ & $\begin{array}{l}1,3635 \\
1,3639 \\
\end{array}$ & $\begin{array}{c}69-70 \\
70 \\
\end{array}$ & NA & F-03/2020 & 7,63 \\
\hline AG-2 & $\begin{array}{c}20,2(\mathrm{P}) \\
19,74(\mathrm{~B}) \\
\end{array}$ & $\begin{array}{l}1,3642 \\
1,3634 \\
\end{array}$ & $\begin{array}{c}70 \\
68-70 \\
\end{array}$ & $\begin{array}{l}\text { NA } \\
\text { NA } \\
\end{array}$ & $02 / 2022$ & 7,91 \\
\hline AG- 3 & $\begin{array}{c}20,0(\mathrm{P}) \\
20,00(\mathrm{~B}) \\
\end{array}$ & $\begin{array}{l}1,3638 \\
1,3639 \\
\end{array}$ & $\begin{array}{l}70 \\
70 \\
\end{array}$ & $\begin{array}{l}\text { NA } \\
\text { NA } \\
\end{array}$ & 28/0420(F) & 6,79 \\
\hline AG-4* & $\begin{array}{c}20,2(\mathrm{P}) \\
20,00(\mathrm{~B}) \\
\end{array}$ & $\begin{array}{l}1,3642 \\
1,3639 \\
\end{array}$ & $\begin{array}{l}70 \\
70 \\
\end{array}$ & $\begin{array}{l}\text { NA } \\
\text { NA } \\
\end{array}$ & & 6,2 \\
\hline AG-5* & $\begin{array}{c}19,4(\mathrm{P}) \\
19,24(\mathrm{~B}) \\
\end{array}$ & $\begin{array}{l}1,3629 \\
1,3625 \\
\end{array}$ & $\begin{array}{l}65-68 \\
65-68 \\
\end{array}$ & $\begin{array}{l}\text { NA } \\
\text { NA } \\
\end{array}$ & $21 / 01 / 2022$ & 6,97 \\
\hline AG-6* & $\begin{array}{c}21,2(\mathrm{P}) \\
21,25(\mathrm{~B}) \\
\end{array}$ & $\begin{array}{l}1,3658 \\
1,3659 \\
\end{array}$ & $\begin{array}{l}70 \\
70 \\
\end{array}$ & $\begin{array}{l}\text { NA } \\
\text { NA } \\
\end{array}$ & $22 / 05 / 2022$ & 8,21 \\
\hline AG-7* & $\begin{array}{c}21,5(\mathrm{P}) \\
21,65(\mathrm{~B}) \\
\end{array}$ & $\begin{array}{l}1,3663 \\
1,3648 \\
\end{array}$ & $\begin{array}{l}70 \\
70 \\
\end{array}$ & $\begin{array}{l}\text { NA } \\
\text { NA }\end{array}$ & $10 / 06 / 22$ & 7,70 \\
\hline AG-8* & $\begin{array}{c}17,0(\mathrm{P}) \\
16,60(\mathrm{~B}) \\
\end{array}$ & $\begin{array}{l}1,3589 \\
1,3585 \\
\end{array}$ & $\begin{array}{l}50-55 \\
45-50 \\
\end{array}$ & $\begin{array}{c}50 \\
46 / 47 \\
\end{array}$ & $27 / 12 / 21$ & 7,98 \\
\hline AG-9a* & $\begin{array}{c}18,4(\mathrm{P}) \\
18,25(\mathrm{~B}) \\
\end{array}$ & $\begin{array}{l}1,3609 \\
1,3610 \\
\end{array}$ & $\begin{array}{l}55-60 \\
55-60 \\
\end{array}$ & \begin{tabular}{|c|}
61 \\
$58 / 57$ \\
\end{tabular} & $03 / 23$ & 6-7 (amostra pouca) \\
\hline AG-9-b & $\begin{array}{c}20,2(\mathrm{P}) \\
20,20(\mathrm{~B}) \\
\end{array}$ & $\begin{array}{l}1,3642 \\
1,3645 \\
\end{array}$ & $\begin{array}{l}70 \\
70 \\
\end{array}$ & $\begin{array}{l}\text { NA } \\
\text { NA }\end{array}$ & $03 / 23$ & 7,47 \\
\hline AG-10* & $\begin{array}{c}19,6(\mathrm{P}) \\
19,12(\mathrm{~B}) \\
\end{array}$ & $\begin{array}{l}1,3632 \\
1,3624 \\
\end{array}$ & $\begin{array}{l}68-70 \\
65-70 \\
\end{array}$ & $\begin{array}{l}\text { NA } \\
70\end{array}$ & $03 / 2022$ & 6,13 \\
\hline AG-11* & $\begin{array}{c}19,5(\mathrm{P}) \\
19,24(\mathrm{~B}) \\
\end{array}$ & $\begin{array}{l}1,3630 \\
1,3625 \\
\end{array}$ & $\begin{array}{l}68-70 \\
68-70 \\
\end{array}$ & $\begin{array}{l}\text { NA } \\
\text { NA } \\
\end{array}$ & $\mathrm{NC}$ & 6,58 \\
\hline AG-12* & $\begin{array}{c}18,4(\mathrm{P}) \\
17,77(\mathrm{~B}) \\
\end{array}$ & $\begin{array}{l}1,3609 \\
1,3604 \\
\end{array}$ & $\begin{array}{l}55-60 \\
55-60 \\
\end{array}$ & \begin{tabular}{|c|}
60 \\
$54 / 55$ \\
\end{tabular} & $03 / 2021$ & 7,05 \\
\hline AG-13* & $\begin{array}{c}20,0(\mathrm{P}) \\
19,77(\mathrm{~B}) \\
\end{array}$ & $\begin{array}{l}1,3638 \\
1,3635 \\
\end{array}$ & $\begin{array}{c}70 \\
69-70 \\
\end{array}$ & $\begin{array}{l}\text { NA } \\
\text { NA }\end{array}$ & $\mathrm{NC}$ & 8,23 \\
\hline AG-14a* & $\begin{array}{c}20,0(\mathrm{P}) \\
20,00(\mathrm{~B}) \\
\end{array}$ & $\begin{array}{l}1,3638 \\
1,3639 \\
\end{array}$ & $\begin{array}{l}69-70 \\
69-70 \\
\end{array}$ & $\begin{array}{l}\text { NA } \\
\text { NA }\end{array}$ & F- 29/12/20 & 6,05 \\
\hline AG-14b & $\begin{array}{c}19,8(\mathrm{P}) \\
19,75(\mathrm{~B}) \\
\end{array}$ & $\begin{array}{l}1,3635 \\
1,3635 \\
\end{array}$ & $\begin{array}{l}69-70 \\
69-70 \\
\end{array}$ & $\begin{array}{l}\text { NA } \\
\text { NA }\end{array}$ & F-20/04/20 & 5,46 \\
\hline AG-15* & $\begin{array}{c}20,6(\mathrm{P}) \\
20,75(\mathrm{~B}) \\
\end{array}$ & $\begin{array}{l}1,3658 \\
1,3650 \\
\end{array}$ & $\begin{array}{l}70 \\
70 \\
\end{array}$ & $\begin{array}{l}\text { NA } \\
\text { NA } \\
\end{array}$ & $\mathrm{NC}$ & 7,58 \\
\hline AG-16* & $\begin{array}{c}19,8(\mathrm{P}) \\
19,56(\mathrm{~B}) \\
\end{array}$ & $\begin{array}{l}1,3635 \\
1,3632 \\
\end{array}$ & $\begin{array}{l}68-70 \\
68-70 \\
\end{array}$ & $\begin{array}{l}\text { NA } \\
\text { NA } \\
\end{array}$ & $06 / 22$ & 6-7 (pouca amostra \\
\hline AG-17* & $\begin{array}{c}19,8(\mathrm{P}) \\
19,78(\mathrm{~B}) \\
\end{array}$ & $\begin{array}{l}1,3635 \\
1,3637 \\
\end{array}$ & $\begin{array}{l}68-70 \\
68-70 \\
\end{array}$ & $\begin{array}{l}\text { NA } \\
\text { NA } \\
\end{array}$ & $08 / 04 / 21$ & 8,35 \\
\hline AG-18* & $\begin{array}{c}19,4(\mathrm{P}) \\
19,26(\mathrm{~B}) \\
\end{array}$ & $\begin{array}{l}1,3628 \\
1,3626 \\
\end{array}$ & $\begin{array}{l}68-70 \\
65-68 \\
\end{array}$ & $\begin{array}{l}\text { NA } \\
\text { NA } \\
\end{array}$ & F-16/03/20 & 6,53 \\
\hline AG-19 & $\begin{array}{c}20,6(\mathrm{P}) \\
20,80(\mathrm{~B}) \\
\end{array}$ & $\begin{array}{c}1,3655 \\
1,364 \\
\end{array}$ & $\begin{array}{l}70 \\
70 \\
\end{array}$ & $\begin{array}{l}\text { NA } \\
\text { NA } \\
\end{array}$ & $11 / 12 / 20$ & 7,31 \\
\hline AG-20 & $\begin{array}{c}20,6(\mathrm{P}) \\
20,74(\mathrm{~B}) \\
\end{array}$ & $\begin{array}{l}1,3659 \\
1,3650 \\
\end{array}$ & $\begin{array}{l}70 \\
70 \\
\end{array}$ & $\begin{array}{l}\text { NA } \\
\text { NA }\end{array}$ & $04 / 23$ & 7,75 \\
\hline AG-21a & $\begin{array}{c}19,8(\mathrm{P}) \\
20,34(\mathrm{~B}) \\
\end{array}$ & $\begin{array}{l}1,3635 \\
1,3645 \\
\end{array}$ & $\begin{array}{c}68-70 \\
70 \\
\end{array}$ & $\begin{array}{l}\text { NA } \\
\text { NA }\end{array}$ & $13 / 04 / 23$ & 5,78 \\
\hline AG-21b & $20,56(\mathrm{~B})$ & 1,3649 & 70 & NA & $15 / 04 / 23$ & 5,74 \\
\hline AG-22 & $\begin{array}{c}19,6(\mathrm{P}) \\
19,76(\mathrm{~B}) \\
\end{array}$ & $\begin{array}{l}1,3631 \\
1,3635 \\
\end{array}$ & $\begin{array}{c}68-70 \\
70 \\
\end{array}$ & $\begin{array}{l}\text { NA } \\
\text { NA }\end{array}$ & $13 / 04 / 23$ & 7,09 \\
\hline AG-23 & $\begin{array}{c}18,8(\mathrm{P}) \\
19,22(\mathrm{~B}) \\
\end{array}$ & $\begin{array}{l}1,3624 \\
1,3625 \\
\end{array}$ & $\begin{array}{l}60-65 \\
68-70 \\
\end{array}$ & $\begin{array}{c}\mathbf{6 5} \\
70 / 69 \\
\end{array}$ & $05 / 22$ & 5,76 \\
\hline
\end{tabular}


Tabela 2. Dados do teor de Brix, índice de refração e pH para diferentes marcas de álcool em gel (cont.)

\begin{tabular}{|c|c|c|c|c|c|c|}
\hline Código da Marca & BRIX $^{* *}$ & Índice de refração *** & $\begin{array}{l}\text { Teor de álcool - } \\
\text { estimado pelos } \\
\text { dados padrões } \\
\end{array}$ & $\begin{array}{c}\text { Teor de álcool - } \\
\text { estimativa pela Equação } 3 \\
\text { (Uso do BX) / IR (B) }\end{array}$ & Validade & $\mathrm{pH}(\text { Faixa } 5-7)^{7}$ \\
\hline AG-24 & $\begin{array}{l}21,2(\mathrm{P}) \\
21,5(\mathrm{~B})\end{array}$ & $\begin{array}{c}1,3658 \\
1,36649\end{array}$ & $\begin{array}{l}70 \\
70\end{array}$ & $\begin{array}{l}\text { NA } \\
\text { NA }\end{array}$ & $04 / 20$ & 7,24 \\
\hline AG-25a & $\begin{array}{c}22,4(\mathrm{P}) \\
21,74(\mathrm{~B})\end{array}$ & $\begin{array}{l}1,3674 \\
1,3665 \\
\end{array}$ & $\begin{array}{l}70 \\
70\end{array}$ & $\begin{array}{l}\text { NA } \\
\text { NA }\end{array}$ & $05 / 2023$ & 7,47 \\
\hline AG-25b- & $\begin{array}{c}22,4(\mathrm{P}) \\
21,10(\mathrm{~B}) \\
\end{array}$ & $\begin{array}{l}1,3674 \\
1,3656 \\
\end{array}$ & 70 & $\begin{array}{l}\text { NA } \\
\text { NA }\end{array}$ & $07 / 23$ & 7,36 \\
\hline AG-26a- & $19,25(\mathrm{~B})$ & 1,3626 & $65-68$ & NA & F-04/20 & 7,50 \\
\hline AG-26b- & $\begin{array}{c}18,4(\mathrm{P}) \\
18,75(\mathrm{~B})\end{array}$ & $\begin{array}{l}1,3612 \\
1,3618\end{array}$ & $\begin{array}{l}60-63 \\
63-65\end{array}$ & $\begin{array}{c}60 \\
63 / 62\end{array}$ & $04 / 22$ & 7,54 \\
\hline AG-27 & $\begin{array}{c}18,0(\mathrm{P}) \\
18,25(\mathrm{~B})\end{array}$ & $\begin{array}{l}1,3606 \\
1,3609\end{array}$ & $\begin{array}{l}55-60 \\
55-60\end{array}$ & $\begin{array}{c}57 \\
58 / 57 \\
\end{array}$ & $04 / 23$ & 7,32 \\
\hline AG-28 & $\begin{array}{c}19,8(\mathrm{P}) \\
19,76(\mathrm{~B})\end{array}$ & $\begin{array}{l}1,3635 \\
1,3635\end{array}$ & $\begin{array}{l}68-70 \\
68-70\end{array}$ & $\begin{array}{l}\mathrm{NA} \\
\mathrm{NA}\end{array}$ & F-04/20 & 6,31 \\
\hline AG-29 & $\begin{array}{c}20,0(\mathrm{P}) \\
20,00(\mathrm{~A}) \\
\end{array}$ & $\begin{array}{l}1,3638 \\
1,3645 \\
\end{array}$ & 70 & $\begin{array}{l}\text { NA } \\
\text { NA }\end{array}$ & $04 / 23$ & 6,56 \\
\hline AG-30 & $\begin{array}{c}19,1(\mathrm{P}) \\
19,75(\mathrm{~B}) \\
\end{array}$ & $\begin{array}{l}1,3622 \\
1,3630 \\
\end{array}$ & $\begin{array}{l}63-68 \\
68-70 \\
\end{array}$ & $\begin{array}{r}69 \\
\text { NA } \\
\end{array}$ & F 06/20 & 8,72 \\
\hline AG-31 & $\begin{array}{c}20,6(\mathrm{P}) \\
22,50(\mathrm{~B}) \\
\end{array}$ & $\begin{array}{l}1,3648 \\
1,3680 \\
\end{array}$ & $\begin{array}{l}70 \\
70 \\
\end{array}$ & $\begin{array}{l}\text { NA } \\
\text { NA }\end{array}$ & F 04/20) & 7,65 \\
\hline AG-32a & $\begin{array}{c}18,4(\mathrm{P}) \\
18,50(\mathrm{~B}) \\
\end{array}$ & $\begin{array}{l}1,3612 \\
1,3613 \\
\end{array}$ & $\begin{array}{l}60-63 \\
60-64 \\
\end{array}$ & $\begin{array}{c}61 \\
60 / 59 \\
\end{array}$ & F 09/20 & 5,81 \\
\hline AG-32b & $\begin{array}{c}18,2(\mathrm{P}) \\
18,70(\mathrm{~B}) \\
\end{array}$ & $\begin{array}{l}1,3609 \\
1,3614 \\
\end{array}$ & $\begin{array}{l}58-60 \\
60-62 \\
\end{array}$ & $\begin{array}{c}59 \\
62 / 60 \\
\end{array}$ & F 09/ 20 & 6,57 \\
\hline AG-32c* & $\begin{array}{c}16,4(\mathrm{P}) \\
16,00(\mathrm{~B})\end{array}$ & $\begin{array}{l}1,3580 \\
1,3573\end{array}$ & \begin{tabular}{|l|}
$45-50$ \\
$45-50$ \\
\end{tabular} & $\begin{array}{c}46 \\
43 / 43 \\
\end{array}$ & $\mathrm{NC}$ & 6,34 \\
\hline AG-33 & $20,89(\mathrm{~B})$ & 1,3655 & 70 & NA & $02 / 23$ & 7,95 \\
\hline AG-34 & $\begin{array}{c}19,6(\mathrm{P}) \\
19,83(\mathrm{~B})\end{array}$ & $\begin{array}{l}1,3632 \\
1,3636\end{array}$ & $\begin{array}{c}68-70 \\
70\end{array}$ & $\begin{array}{l}\text { NA } \\
\text { NA }\end{array}$ & $05 / 23$ & 7,35 \\
\hline AG-35 & $19,75(\mathrm{~B})$ & 1,36349 & 70 & NA & $05 / 23$ & 7,54 \\
\hline AG-36 & $20,46(\mathrm{~B})$ & 1,3645 & 70 & NA & $03 / 22$ & 9,49 \\
\hline AG-37 & $19,75(\mathrm{~B})$ & 1,3638 & 70 & NA & $04 / 23$ & 6,72 \\
\hline AG-38a & $19,95(\mathrm{~B})$ & 1,3638 & 70 & NA & $04 / 22$ & 6,68 \\
\hline AG-38b & $\begin{array}{l}19,40(\mathrm{P}) \\
20,00(\mathrm{~B})\end{array}$ & $\begin{array}{l}1,3629 \\
1,3639\end{array}$ & 70 & $\begin{array}{l}\text { NA } \\
\text { NA }\end{array}$ & $04 / 22$ & 6,56 \\
\hline AG-39 & $17,75(\mathrm{~B})$ & 1,3605 & $50-55$ & $54 / 55$ & $07 / 22$ & 6,61 \\
\hline AG-40 & $20,75(\mathrm{~B})$ & 1,3652 & 70 & NA & $04 / 23$ & 7,15 \\
\hline AG-41a & $\begin{array}{c}18,9(\mathrm{P}) \\
19,00(\mathrm{~B})\end{array}$ & $\begin{array}{l}1,3623 \\
1,3627\end{array}$ & $\begin{array}{l}63-65 \\
63-65 \\
\end{array}$ & $\begin{array}{c}67 \\
66 / 67\end{array}$ & $05 / 23$ & 7,78 \\
\hline AG-41b & $\begin{array}{c}19,0(\mathrm{P}) \\
19,45(\mathrm{~B})\end{array}$ & $\begin{array}{l}1,3623 \\
1,3625\end{array}$ & $\begin{array}{l}63-65 \\
68-70 \\
\end{array}$ & $\begin{array}{r}\mathbf{6 8} \\
\mathrm{NA}\end{array}$ & $04 / 23$ & 7,78 \\
\hline AG-42 & $\begin{array}{c}19,2(\mathrm{P}) \\
19,30(\mathrm{~B}) \\
\end{array}$ & $\begin{array}{l}1,3619 \\
1,3620 \\
\end{array}$ & $\begin{array}{l}70 \\
70 \\
\end{array}$ & NA & $06 / 22$ & 7,32 \\
\hline AG-43 & $19,60(\mathrm{~B})$ & 1,3635 & 70 & NA & $04 / 23$ & 6,66 \\
\hline AG-44 & $\begin{array}{c}18,8(\mathrm{P}) \\
19,00(\mathrm{~B})\end{array}$ & $\begin{array}{l}1,3619 \\
1,3622 \\
\end{array}$ & $\begin{array}{l}60-65 \\
65-68 \\
\end{array}$ & $\begin{array}{c}65 \\
66 / 66 \\
\end{array}$ & $04 / 22$ & 5,46 \\
\hline AG-45 & $\begin{array}{c}20,0(\mathrm{P}) \\
20,00(\mathrm{~B})\end{array}$ & $\begin{array}{l}1,3638 \\
1,3639\end{array}$ & 70 & $\begin{array}{l}\text { NA } \\
\text { NA }\end{array}$ & $05 / 2023$ & 5,99 \\
\hline AG-46 & $\begin{array}{c}20,6(\mathrm{P}) \\
21,23(\mathrm{~B})\end{array}$ & $\begin{array}{l}1,3648 \\
1,3658\end{array}$ & 70 & $\begin{array}{l}\text { NA } \\
\text { NA }\end{array}$ & $04 / 20$ & 8,36 \\
\hline AG-47 & $\begin{array}{c}20,0(\mathrm{P}) \\
20,25(\mathrm{~B})\end{array}$ & $\begin{array}{l}1,3638 \\
1,3641\end{array}$ & 70 & $\begin{array}{l}\text { NA } \\
\text { NA }\end{array}$ & F-06/20 & 7,02 \\
\hline AG-48a & $\begin{array}{c}19,0(\mathrm{P}) \\
19,90(\mathrm{~B})\end{array}$ & $\begin{array}{l}1,3632 \\
1,3637\end{array}$ & $\begin{array}{c}65-70 \\
70\end{array}$ & $\begin{array}{r}68 \\
\text { NA }\end{array}$ & $04 / 2022$ & 7,20 \\
\hline AG-48b & $\begin{array}{c}19,8(\mathrm{P}) \\
19,90(\mathrm{~B})\end{array}$ & $\begin{array}{l}1,3635 \\
1,3637\end{array}$ & $68-70$ & $\begin{array}{l}\text { NA } \\
\text { NA }\end{array}$ & $04 / 2022$ & 7,20 \\
\hline AG-49 & $\begin{array}{c}19,6(\mathrm{P}) \\
20,25(\mathrm{~B})\end{array}$ & $\begin{array}{l}1,3632 \\
1,3648\end{array}$ & $\begin{array}{c}68-70 \\
70\end{array}$ & $\begin{array}{l}\text { NA } \\
\text { NA }\end{array}$ & $05 / 22$ & 5,94 \\
\hline AG-50 & $\begin{array}{c}20,0(\mathrm{P}) \\
20,25(\mathrm{~B})\end{array}$ & $\begin{array}{c}1,3638 \\
1,36454\end{array}$ & $\begin{array}{l}70 \\
70\end{array}$ & $\begin{array}{l}\text { NA } \\
\text { NA }\end{array}$ & $04 / 22$ & 7,40 \\
\hline AG-51 & $\begin{array}{l}20,40(\mathrm{P}) \\
20,75(\mathrm{~B})\end{array}$ & $\begin{array}{l}1,3644 \\
1,3651\end{array}$ & $\begin{array}{l}70 \\
70\end{array}$ & $\begin{array}{l}\text { NA } \\
\text { NA }\end{array}$ & $\mathrm{NC}$ & 6,76 \\
\hline
\end{tabular}


Tabela 2. Dados do teor de Brix, índice de refração e pH para diferentes marcas de álcool em gel (cont.)

\begin{tabular}{|c|c|c|c|c|c|c|}
\hline Código da Marca & BRIX $^{* *}$ & Índice de refração ${ }^{* * *}$ & $\begin{array}{l}\text { Teor de álcool - } \\
\text { estimado pelos } \\
\text { dados padrões }\end{array}$ & $\begin{array}{c}\text { Teor de álcool - } \\
\text { estimativa pela Equação } 3 \\
\text { (Uso do BX) / IR (B) }\end{array}$ & Validade & $\mathrm{pH}(\text { Faixa } 5-7)^{7}$ \\
\hline AG-52 & $\begin{array}{c}19,6(\mathrm{P}) \\
20,50(\mathrm{~B})\end{array}$ & $\begin{array}{l}1,3632 \\
1,3647\end{array}$ & $\begin{array}{c}68-70 \\
70\end{array}$ & $\begin{array}{l}\text { NA } \\
\text { NA }\end{array}$ & $20 / 10 / 20$ & 6,95 \\
\hline AG-53 & $\begin{array}{c}20,4(\mathrm{P}) \\
20,76(\mathrm{~B})\end{array}$ & $\begin{array}{l}1,3644 \\
1,3656\end{array}$ & 70 & $\begin{array}{l}\text { NA } \\
\text { NA }\end{array}$ & $06 / 2023$ & 7,38 \\
\hline AG-54 ${ }^{a}$ & $\begin{array}{c}18,8(\mathrm{P}) \\
19,00(\mathrm{~B}) \\
\end{array}$ & $\begin{array}{l}1,3619 \\
1,3623 \\
\end{array}$ & $\begin{array}{l}60-65 \\
65-68 \\
\end{array}$ & $\begin{array}{c}65 \\
66 / 67 \\
\end{array}$ & F-29/01/21 & 7,27 \\
\hline AG-54b* & $\begin{array}{c}18,8(\mathrm{P}) \\
18,90(\mathrm{~B})\end{array}$ & $\begin{array}{l}1,3619 \\
1,3620 \\
\end{array}$ & $\begin{array}{l}60-63 \\
65-67 \\
\end{array}$ & $\begin{array}{c}65 \\
65 / 64 \\
\end{array}$ & $\mathrm{NC}$ & 5,18 \\
\hline AG-55 & $\begin{array}{c}20,2(\mathrm{P}) \\
20,80(\mathrm{~B}) \\
\end{array}$ & $\begin{array}{l}1,3642 \\
1,3654 \\
\end{array}$ & $\begin{array}{l}70 \\
70 \\
\end{array}$ & $\begin{array}{l}\text { NA } \\
\text { NA }\end{array}$ & F-12/03/21 & 7,32 \\
\hline AG-56 & $\begin{array}{c}19,8(\mathrm{P}) \\
19,75(\mathrm{~B}) \\
\end{array}$ & $\begin{array}{l}1,3635 \\
1,3635 \\
\end{array}$ & $\begin{array}{l}68-70 \\
68-70 \\
\end{array}$ & $\begin{array}{l}\text { NA } \\
\text { NA }\end{array}$ & $06 / 21$ & 6,53 \\
\hline AG-57 & $\begin{array}{c}19,4(\mathrm{P}) \\
19,50(\mathrm{~B}) \\
\end{array}$ & $\begin{array}{l}1,3629 \\
1,3630 \\
\end{array}$ & $\begin{array}{l}68-70 \\
68-70 \\
\end{array}$ & $\begin{array}{l}\text { NA } \\
\text { NA } \\
\end{array}$ & F-04/20 & 6,46 \\
\hline AG-58 & $\begin{array}{c}18,6(\mathrm{P}) \\
19,00(\mathrm{~B}) \\
\end{array}$ & $\begin{array}{l}1,3612 \\
1,3624 \\
\end{array}$ & $\begin{array}{l}60-63 \\
65-68 \\
\end{array}$ & $\begin{array}{c}63 \\
66 / 67 \\
\end{array}$ & $04 / 22$ & 8,21 \\
\hline AG-59 & $\begin{array}{c}20,2(\mathrm{P}) \\
20,00(\mathrm{~B}) \\
\end{array}$ & $\begin{array}{l}1,3642 \\
1,3640 \\
\end{array}$ & $\begin{array}{l}70 \\
70 \\
\end{array}$ & $\begin{array}{l}\text { NA } \\
\text { NA } \\
\end{array}$ & F-07/20 & 6,39 \\
\hline AG-60 & $\begin{array}{c}20,0(\mathrm{P}) \\
19,50(\mathrm{~B}) \\
\end{array}$ & $\begin{array}{l}1,3638 \\
1,3635 \\
\end{array}$ & $\begin{array}{l}70 \\
70 \\
\end{array}$ & $\begin{array}{l}\text { NA } \\
\text { NA } \\
\end{array}$ & F-03/21 & 7,43 \\
\hline AG-61 & $\begin{array}{c}19,8(\mathrm{P}) \\
20,00(\mathrm{~B}) \\
\end{array}$ & $\begin{array}{l}1,3635 \\
1,3637 \\
\end{array}$ & $\begin{array}{l}70 \\
70 \\
\end{array}$ & $\begin{array}{l}\text { NA } \\
\text { NA } \\
\end{array}$ & $26 / 04 / 22$ & 6,64 \\
\hline AG-62 & $\begin{array}{c}20,0(\mathrm{P}) \\
19,50(\mathrm{~B}) \\
\end{array}$ & $\begin{array}{l}1,3638 \\
1,3630 \\
\end{array}$ & $\begin{array}{c}70 \\
68-70 \\
\end{array}$ & $\begin{array}{l}\text { NA } \\
\text { NA }\end{array}$ & $08 / 04 / 21$ & 8,36 \\
\hline AG-63 & $\begin{array}{c}16,8(\mathrm{P}) \\
17,24(\mathrm{~B}) \\
\end{array}$ & $\begin{array}{l}1,3586 \\
1,3592 \\
\end{array}$ & $\begin{array}{l}45-50 \\
50-55 \\
\end{array}$ & $\begin{array}{c}48 \\
50 / 49 \\
\end{array}$ & $03 / 04 / 22$ & 7,78 \\
\hline AG-64 & $\begin{array}{c}18,8(\mathrm{P}) \\
18,60(\mathrm{~B})\end{array}$ & $\begin{array}{l}1,3619 \\
1,3615\end{array}$ & $\begin{array}{l}63-65 \\
60-63\end{array}$ & $\begin{array}{c}65 \\
61 / 60\end{array}$ & F-10/07/20 & 7,58 \\
\hline AG-65 & $\begin{array}{c}19,6(\mathrm{P}) \\
19,75(\mathrm{~B}) \\
\end{array}$ & $\begin{array}{l}1,3632 \\
1,3635 \\
\end{array}$ & $\begin{array}{c}68-70 \\
70 \\
\end{array}$ & $\begin{array}{l}\text { NA } \\
\text { NA } \\
\end{array}$ & $02 / 24$ & 8,23 \\
\hline AG-66 & $\begin{array}{c}20,0(\mathrm{P}) \\
19,60(\mathrm{~B}) \\
\end{array}$ & $\begin{array}{l}1,3638 \\
1,3634 \\
\end{array}$ & $\begin{array}{c}70 \\
68-70 \\
\end{array}$ & $\begin{array}{l}\text { NA } \\
\text { NA }\end{array}$ & $04 / 23$ & 7,49 \\
\hline AG-67 & $\begin{array}{c}19,2(\mathrm{P}) \\
19,10(\mathrm{~B}) \\
\end{array}$ & $\begin{array}{l}1,3611 \\
1,3625 \\
\end{array}$ & $\begin{array}{l}68-70 \\
68-70 \\
\end{array}$ & $\begin{array}{l}74 \\
71 \\
\end{array}$ & $04 / 23$ & 6,25 \\
\hline AG-68 & $\begin{array}{c}19,6(\mathrm{P}) \\
19,75(\mathrm{~B}) \\
\end{array}$ & $\begin{array}{l}1,3632 \\
1,3635 \\
\end{array}$ & $\begin{array}{c}68-70 \\
70 \\
\end{array}$ & $\begin{array}{l}\text { NA } \\
\text { NA }\end{array}$ & F-04/20 & 6,39 \\
\hline AG-69 & $\begin{array}{l}19,8(\mathrm{P}) \\
20,0(\mathrm{~B}) \\
\end{array}$ & $\begin{array}{l}1,3635 \\
1,3637 \\
\end{array}$ & $\begin{array}{l}70 \\
70 \\
\end{array}$ & $\begin{array}{l}\text { NA } \\
\text { NA }\end{array}$ & F-05/20 & 7,34 \\
\hline AG-70a & $\begin{array}{c}20,2(\mathrm{P}) \\
20,00(\mathrm{~B}) \\
\end{array}$ & $\begin{array}{l}1,3642 \\
1,3645 \\
\end{array}$ & $\begin{array}{l}70 \\
70 \\
\end{array}$ & $\begin{array}{l}\text { NA } \\
\text { NA }\end{array}$ & F-02/20 & 7,02 \\
\hline AG-70b & $\begin{array}{c}20,2(\mathrm{P}) \\
20,20(\mathrm{~B}) \\
\end{array}$ & $\begin{array}{l}1,3642 \\
1,3645 \\
\end{array}$ & $\begin{array}{l}70 \\
70 \\
\end{array}$ & $\begin{array}{l}\text { NA } \\
\text { NA }\end{array}$ & F-11/20 & 6,98 \\
\hline AG-70c* & $18,2(\mathrm{P})$ & 1,3609 & $58-60$ & 58 & $\mathrm{~F}-11 / 08 / 20$ & \\
\hline IQ - UFBA & $\begin{array}{l}20,60(\mathrm{P}) \\
20,35(\mathrm{~B}) \\
\end{array}$ & $\begin{array}{l}1,3648 \\
1,3645 \\
\end{array}$ & $\begin{array}{l}70 \\
70 \\
\end{array}$ & $\begin{array}{l}\text { NA } \\
\text { NA }\end{array}$ & $\begin{array}{l}4 \text { lotes- F-11 e } 12 / 20 \\
\text { e } 2 \text { lotes } 01 \text { e } 02 / 21\end{array}$ & $6,50-6,70$ \\
\hline
\end{tabular}

*Disponível para clientes AG- álcool em gel; F- fabricação. NC- não consta. NA- não aplicado - valor acima do intervalo dos dados da curva.padrão. P- Refratômetro portátil. B- Refratômetro de bancada. Célula em negrito - inadequado quanto ao teor de álcool. ${ }^{8}$ Célula em itálico- inadequado quanto a pH. ${ }^{7 *}$ * Desvio padrão e limite de detecção $\left({ }^{\circ} \mathrm{BX}\right)-8,3 \times 10^{-3}$ e 0 (inferior- $(\mathrm{P}$ e B) $) / 32(\mathrm{P})$ e 95 (B)(superior). ***Desvio padrão e limite de detecção (IR (B)) - 2,5x10 ${ }^{-4}$ e 1,330 (inferior)/1,530 (superior).

indicaram que 16 marcas $(22,85 \%)$ e 19 amostras $(22,89 \%)$ não apresentaram o teor de álcool adequado para assepsia das mãos, visto que o álcool etílico se encontra abaixo do limite $68,25^{\circ}$ INPM. ${ }^{9}$ Os resultados indicaram que 37 marcas $(52,85 \%)$ (40 amostras $(57,14 \%)$ ), apresentaram $\mathrm{pH}$ inadequado ao $\mathrm{pH}$ cutâneo e não seguem a recomendação citado na Farmacopeia Brasileira. ${ }^{7}$

$\mathrm{O}$ índice de refração é uma propriedade física que pode ser utilizada na caracterização e identificação da pureza de líquidos, sendo definido como a razão entre a velocidade da luz no vácuo e na substância analisada devido a interação de ondas eletromagnéticas com a matéria, ${ }^{13}$ assim os componentes como a glicerina, dipropilenoglicol, e álcool isopropanol, presentes na formulação do álcool em gel, contribuem para valores de índice de refração superior a mistura binária água - álcool etílico $(70 \%(\mathrm{~m} / \mathrm{m}))$. Esses componentes têm valores índice de refração de 1,47, 1,43 e 1,378. ${ }^{16} \mathrm{~A}$ afirmação sobre o teor do álcool nas marcas apresentadas na Tabela 2 com os valores de Brix acima de 21 e IR acima de 1,3656 e um aspecto homogêneo com várias bolhas pode ser indicativo de excesso de glicerina, assim o teor de álcool para essas marcas requer outro método para a busca de uma afirmação segura, conforme descrito a seguir. Medidas de IR e teor de ${ }^{\circ} \mathrm{BX}$ para duas soluções aquosas: uma contendo $10 \%(\mathrm{~m} / \mathrm{m})$ de glicerina (I) e outra com $10 \%(\mathrm{~m} / \mathrm{m})$ de dipropilenoglicol (II), resultaram em 5,2 ( $\left.{ }^{\circ} \mathrm{BX}\right)$ e 1,3435 (IR) para I e $5,323\left({ }^{\circ} \mathrm{BX}\right)$ e 1,3450 (IR) para II. 
É importante ressaltar que a glicerina é o emoliente mais usado na formulação do álcool em gel, porém uma concentração alta de glicerina, como $1,45 \%$ em massa apresenta efeitos prejudiciais, pois pode diminuir o tempo de secagem e aumentar a sensação pegajosa da pele. Estudos mostraram que o uso de glicerina com concentrações de $0,50 \%$ a $0,73 \%$ mantém a atividade antimicrobiana do álcool em gel e ainda oferece a proteção necessária à pele ${ }^{1}$. $\mathrm{O}$ tempo de secagem do álcool em gel pode alterar de 20-60 s, no entanto, tempo superior também pode ser devido ao excesso de glicerina. ${ }^{1}$

\section{Análise do teor de álcool etílico no álcool em gel-Reação de oxirredução}

A determinação do teor de álcool etílico nas diferentes marcas de álcool em gel por meio de uma reação de oxirredução, tendo com oxidante o ânion dicromato, é termodinamicamente favorecida e é o princípio básico do funcionamento do bafômetro, cuja reação global do processo químico está representada na Equação I.

É importante destacar que embora os emolientes usados na composição de diferentes marcas também reagem com o ânion dicromato e resulta o $\mathrm{Cr}^{3+}(\mathrm{aq})$, como o teor dos mesmos é muito pequena se comparada ao teor do álcool, a contribuição para as leituras da absorvância em $582 \mathrm{~nm}$ é desprezível. Essa afirmação foi confirmada com o registro dos espectros eletrônicos de soluções aquosas contendo esses emolientes, após mistura com o ânion dicromato e reação por 60 minutos. O perfil dos espectros não indicou a formação de $\mathrm{Cr}$ (III) ou seja o consumo do oxidante não é expressivo.

Para o controle de qualidade de antissépticos para as mãos, a refratometria e o método de oxidação do álcool pelo dicromato são metodologias complementares. Como um método de triagem, a refratometria é uma técnica mais adequada para detectar a não conformidade na formulação do álcool em gel relacionado ao conteúdo do etanol. No entanto, a interferência de emolientes pode afetar a precisão da determinação do teor de etanol. Considerando esse aspecto, neste trabalho, para uma afirmação inequívoca, um número razoável, entre as 70 marcas, foi selecionado para a determinação do teor de álcool, por meio da oxidação da molécula de etanol.

\section{Álcool em gel - produção no Instituto de Química (IQ) da UFBA}

$O$ índice de refração e teor de brix para diferentes lotes do referido produto indicaram conter álcool $70 \%(\mathrm{~m} / \mathrm{m})$. A análise por meio da oxidação da molécula do etanol pelo dicromato resultou em solução azul com bandas de absorção em $582 \mathrm{~nm}$ e $412 \mathrm{~nm}$ indicativo da formação do crômio(III). A cor da solução e o perfil do espectro eletrônico são coerentes com a solução padrão contendo entre 70$75 \%$ em massa do álcool etílico (Figura 3). O teor calculado com base na Equação 5 tomando como base a absorvância obtida após correção das linhas de base das curvas foi de $73 \%(\mathrm{~m} / \mathrm{m})$. Em função

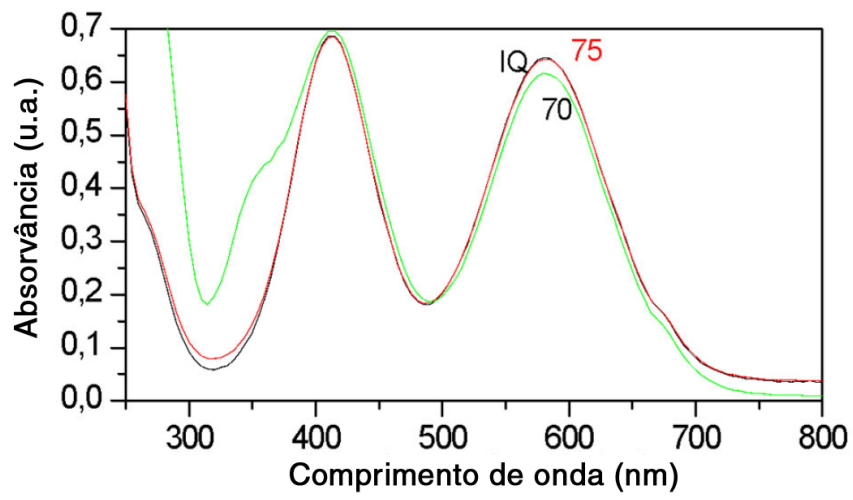

Figura 3. Espectros eletrônicos para as soluções álcool em gel IQ-UFBA, 70 e $75 \%(\mathrm{~m} / \mathrm{m})$ em álcool após reação com dicromato dos dados apresentados por refratometria e reação de oxirredução o produto produzido no IQ -UFBA é adequado para assepsia das mãos e atende o recomendado pela $\mathrm{OMS}^{4}$ e ANVISA. ${ }^{9}$

Álcool em gel-AG-1b; $A G-3 ; A G-6 ; A G-9-b ; A G-10 ; A G-14 b$; $A G-20 ; A G-23 ; A G-24 ; A G-33 ; A G-36 ; A G-38 ; A G-50 ; A G-51$; $A G-60 ; A G-61 ;$ e $A G-68$

As análises para o álcool em gel das marcas selecionadas, resultaram em teor de Brix e índice de refração consistentes com uma porcentagem de álcool etílico no produto de $70 \%(\mathrm{~m} / \mathrm{m})$ ou com pequena diferença como em AG-10. Uma vez que os emolientes (dipropilenoglicol e glicerina), usados nas formulações das diferentes marcas de álcool em gel, podem contribuir para uma afirmação não segura em relação ao teor de álcool etílico quando se usa a refratometria, a metodologia descrita para estimar o teor do álcool por meio de reação de oxirredução foi aplicada. Uma mistura de solução aquosa ácida de dicromato com solução do álcool em gel foi efetuada e após uma hora de reação os espectros eletrônicos foram registrados.

Os espectros eletrônicos para as soluções álcool em gel das marcas indicadas e soluções 70 e $75 \%$ ou 65 e $75 \%$ ou 65 e $70 \%$ em massa do álcool após reação com dicromato, foram comparados e o teor do álcool etílico foi determinado. Com base na absorvância obtida após correção das linhas de base das curvas e aplicação na Equação 5, resultaram teores em massa para o álcool etílico de 71 (AG-1b); 71 (AG-3); 74/73 (AG-6), 69/70 (AG-9b); 69 (AG-10), 69 (AG-14); 72 (AG-20); 69 (AG-23), 70/69 (AG 24); 70 (AG-31); 70/71 (AG33) 71(AG 36) 72 (AG -38); 71 (AG-50); 69 (AG 60) 71 (AG-61) e 71 (AG-68). Para as marcas nas quais estão indicados dois valores para o teor do álcool etílico, além da correção da linha de base dos espectros, foi aplicado na Equação 5 o valor médio das absorvâncias resultantes das análises efetuadas em triplicata ou superior.

No rótulo da marca AG-10 foi indicado que o teor do álcool é 80 'INPM, porém, o valor obtido por meio da oxidação do álcool é menor, no entanto, dentro da faixa que atende as recomendações da ANVISA. ${ }^{9} \mathrm{Na}$ Figura 4 é possível comparar os perfis entre os espectros eletrônicos para as curvas das soluções de referência e da referida marca após reação com dicromato. No rótulo da marca AG-20 os valores $70{ }^{\circ} \mathrm{GL}$ e $62^{\circ} \mathrm{INPM}$ foram especificados para o teor de álcool, porém as análises por refratometria e oxirredução indicaram 70 e $72{ }^{\circ} \mathrm{INPM}$, essa informação errada indicaria que o produto apresenta teor de álcool etílico abaixo do valor limite para assepsia das mãos.

Para a marca AG-9 duas amostras foram analisadas. A amostra 9a que foi encontrada disponível para uso do cliente em um estabelecimento em Salvador, foi avaliada por refratometria e os teores de álcool (Tabela 2) abaixo do recomendado pela ANVISA. ${ }^{9}$ Por outro lado, o produto AG-9b apresentou teor de Brix consistente com álcool 70 INPM. Em função da diferença apresentada para a referida marca uma avaliação por meio da oxidação do álcool com dicromato foi efetuada, a fim de buscar uma afirmação inequívoca do teor do álcool etílico. A solução resultante da reação de oxirredução apresentou uma coloração azul e o espectro eletrônico foi registrado. Uma comparação das curvas absorvância versus comprimento de onda para as soluções álcool em gel AG-9b, 65 e $75 \%(\mathrm{~m} / \mathrm{m})$ em álcool após reação com dicromato é ilustrada na Figura 9S. O teor de álcool etílico $(69 / 70 \%(\mathrm{~m} / \mathrm{m}))$ se encontra dentro do recomendado pela ANVISA ${ }^{9}$ e contribui para evitar a transmissão do SARS-CoV-2.

Álcool em gel-AG-12; $A G-26(a, b) ; A G-27 ; A G-32(a, b, c)$; $A G-39 ; A G-41 a ; A G-44 ; A G-54(a, b) ; A G-58 ; A G-63 ; A G-64$

As referidas marcas de álcool em gel selecionadas para estudo apresentaram valores de Brix e índice de refração correspondentes 


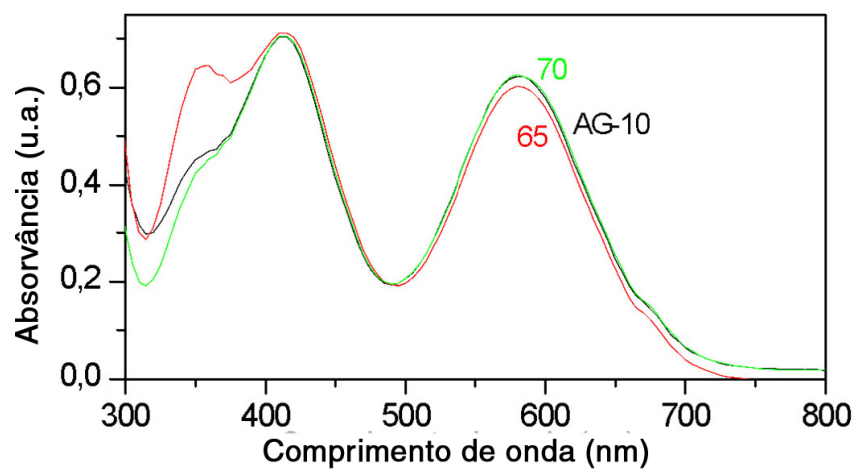

Figura 4. Espectros eletrônicos para as soluções álcool em gel AG-10, 65 e $70 \%(\mathrm{~m} / \mathrm{m})$ em álcool após reação com dicromato

aos teores de etanol (Tabela 2) abaixo do recomendado pela ANVISA, $68,25 \%(\mathrm{~m} / \mathrm{m}){ }^{9}$

No sentido de buscar uma afirmação mais segura sobre a não eficiência das marcas para assepsia das mãos o teor de álcool etílico foi determinado por meio de oxidação com uso de dicromato. Após uma hora de reação das soluções de AG-12, 39, 32c e 63 com o oxidante resultaram soluções de coloração amarelo esverdeada. As soluções resultantes da reação entre as soluções de AG-41, 58 e 69 com dicromato apresentaram coloração azul esverdeada. Uma comparação entre os espectros eletrônicos das soluções álcool em gel com as soluções de referência após reação com dicromato foi realizada para determinar o teor de álcool etílico.

Com base na média dos valores de absorvância e ou nas absorvâncias obtidas após correção das linhas de base das curvas e aplicados na Equação 4 resultaram nos seguintes teores em massa para o álcool etílico - 48/50 (AG-12); 58/59 e 58/56 (AG 26-(a, b)), 56 (AG-27); 56/57; 56/57 e 43 (AG-32-(a, b, c)); 48 (AG-39); 66/67 (AG-41a); 53/52 (AG-44); 54/55 e 56 (AG-54(a, b)); 65/62 (AG-58); 47/48 (AG-63); 57/57 (AG-64). O uso da Equação 5 foi aplicado para a marca $A G-41$.

Para a marca AG-32, a qual tem aparência muito boa, três amostras foram avaliadas. A amostra AG-32c, disponível para o uso do cliente, apresentou um teor de álcool etílico menor, do que as amostras dos frascos lacrados - AG-32(a, b). Para a marca AG-26(a, b), foram usados 2 lotes com os frascos lacrados, chegando aos seguintes resultados: (I) teores de álcool etílico encontrados por refratometria semelhantes e (II) os teores determinados pela oxidação com uso do dicromato similares. Entretanto, os valores obtidos com uso das duas metodologias são diferentes. A presença de dipropilenoglicol na formulação, cujo teor não é indicado no rótulo, deve ter contribuído para teores mais altos de álcool etílico quando a refratometria foi aplicada (Tabela 2).

A marca AG-54 pode ser encontrada em vários estabelecimentos da cidade de Salvador e com um valor de compra bastante atrativo. Uma análise rápida como a refratometria mostrou que o teor de álcool etílico na mesma foi aquém do valor de referência ${ }^{9}$ essa mesma afirmação é válida para a marca AG-63, cuja sensação nas mãos do consumidor não é nada agradável. A Figura $10 \mathrm{~S}$ ilustra os perfis dos espectros eletrônicos para os produtos da reação - dicromato com AG-63 e dicromato com soluções aquosas - álcool 45 e $55 \%$ (m/m).

Álcool em gel- $A G-30 ; A G-42 ; A G-55 ; A G-62 ; A G-65 ; A G-66$; AG-69 e $A G-70(a, b)$

As marcas selecionadas apresentaram valores de Brix e índice de refração correspondentes aos teores $68-70 \%(\mathrm{~m} / \mathrm{m})$ para AG-30 e AG-66 e para as demais $70 \%(\mathrm{~m} / \mathrm{m})$ (Tabela 2) em etanol. As análises por meio oxidação do álcool etílico com uso de dicromato, resultaram em teores abaixo do valor de referência $68,25 \%(\mathrm{~m} / \mathrm{m}) .{ }^{9}$ A tomada de decisão para a aplicação da metodologia por oxirredução foi associada em alguns casos à aparência do produto com várias bolhas e outras à sensação pegajosa nas mãos. Esses aspectos podem ser indicativos do uso de uma proporção não adequada de glicerina na formulação do álcool em gel.

Foram realizadas comparações do perfil da curva absorvância versus comprimento de onda para as soluções álcool em gel, 70-75\% ou $65-70 \%$ ou $60-65 \%(\mathrm{~m} / \mathrm{m})$ em álcool após reação com dicromato. Com base na absorvância, após correção das linhas de base das curvas, e ou valor médio de 4 análises e aplicados na Equação 4 (teores de álcool abaixo de $60 \%$ (m/m) ou Equação 5, as diferentes marcas apresentaram os seguintes teores em massa de álcool etílico: 58/57(AG-30); 62/64 (AG-42); 66/64 (AG-55); 66 (AG-62); 56/56 (AG-65); 65 (AG-66); 61/60 (AG-69) e 56 e 59 (AG-70 (a, b).

A Figura 11S ilustra os espectros dos produtos da reação dicromato - álcool em gel (AG-30) e dicromato - soluções 60 e $65 \%$ em massa de álcool etílico. O teor de álcool etílico apresentado por refratometria é consistente com $68-70 \%(\mathrm{~m} / \mathrm{m})$, diferente do valor determinado por oxirredução (58/57), portanto, não segue a recomendação da ANVISA, ${ }^{9}$ e assim o produto não realiza assepsia das mãos.

Para a marca AG-55 foi também avaliado o produto na forma líquida AL-10, o qual é comercializado como saneante. No rótulo dos dois produtos é especificado o valor $70^{\circ} \mathrm{INPM}$ para o teor álcool. Para a forma líquida, além da aplicação refratometria para determinar o teor de álcool etílico, foi usado o alcoolômetro e determinação por meio da oxidação com uso de dicromato. Os valores indicaram teor de álcool etílico inferior ao recomendado na resolução 422 da ANVISA. ${ }^{9}$ Os resultados indicaram que a informação do rótulo não era verdadeira e o teor 70 se tratava na verdade da porcentagem em volume $70{ }^{\circ} \mathrm{GL}$, o que corresponde ao teor de álcool ao converter as unidades $(64 \% \mathrm{~m} / \mathrm{m})$ e também estimados por meio de oxirredução $(64-66 \%(\mathrm{~m} / \mathrm{m}))$ e abaixo daquele estimado por refratometria (Tabela 2).

A Tabela 3 ilustra um comparativo entre os teores de álcool em gel encontrado por refratometria e oxirredução para as marcas selecionadas.

Das 36 marcas apresentadas na Tabela 3, para as quais foram aplicadas as 2 metodologias, a fim de determinar o teor de álcool etílico, os dados indicam que: i-17 marcas $(47,22 \%)$ têm os valores similares e o teor de álcool etílico dentro do recomendado. ${ }^{9}$ ii- 11 marcas $(30,55 \%$, ) apresentaram com a aplicação da refratometria um teor de álcool etílico inferior ao limite recomendado pelo Ministério da Sáude/ANVISA. ${ }^{9}$ Os valores (Tabela 3) abaixo do recomendado foram confirmados por meio da oxidação do álcool com o dicromato, embora com certa discrepância entre as duas metodologias.

Com base nos dispostos acima (i e ii) é possível afirmar que $77,77 \%$ das marcas avaliadas apresentaram resultados confiáveis utilizando a refratometria. É importante destacar que a metodologia fornece uma informação rápida e se aplicada pela vigilância sanitária (Município e/ou Estado), com encaminhamentos aos órgãos competentes, sem dúvida, um menor número de produtos inadequados, para assepsia das mãos, seriam encontrados no mercado.

Embora a refratometria tenha fornecido resultados confiáveis para $77,77 \%$ das marcas, nas situações cuja formulação possui concentração de emoliente acima do recomendado, os teores de álcool etílico não são garantidos. Na Tabela 3 há 8 marcas $(22,22 \%)$ que resultaram produtos eficientes para assepsia das mãos, no entanto, a reação de oxirredução dicromato com álcool em gel, indicou teores de etanol aquém do recomendado. ${ }^{9}$

A Tabela 4 ilustra as marcas cujos teores de etanol encontrados por refratometria e ou oxirredução indicaram produtos não efetivos para assepsia das mãos em meio à pandemia. Essa tabela foi construída 
Tabela 3. Comparativo entre os teores de álcool em gel encontrado por refratometria e oxirredução

\begin{tabular}{|c|c|c|}
\hline Marcas & $\begin{array}{l}\text { Teor de álcool etílico } \\
(\mathrm{m} / \mathrm{m}) \text { por refratometria } \\
\text { - refratômetro de } \\
\text { bancada }(\text { Brix/IR) }\end{array}$ & $\begin{array}{l}\text { Teor de álcool }(\mathrm{m} / \mathrm{m}) \text { por } \\
\text { reação de oxirredução } \\
\text { (correção espectro / } \\
\text { média de absorvância }\end{array}$ \\
\hline Instituto de Química & 70 & 73 \\
\hline AG-1b- & 70 & 71 \\
\hline AG-3 & 70 & 71 \\
\hline AG-6 & 70 & $74 / 73$ \\
\hline AG-9b & 70 & $70 / 69$ \\
\hline AG-10* & 70 & 69 \\
\hline AG-12* & $54 / 55$ & $50 / 48$ \\
\hline AG-14b & $69-70$ & 69 \\
\hline AG-20 & 70 & 72 \\
\hline AG- 23 & $70 / 69$ & 69 \\
\hline AG-24 & 70 & $69 / 70$ \\
\hline AG-26a & $65-68$ & $59 / 58$ \\
\hline AG-26b & $63 / 62$ & $56 / 58$ \\
\hline AG-27 & $58 / 57$ & 56 \\
\hline AG-30 & $68-70$ & $58 / 57$ \\
\hline AG-32a & $60 / 59$ & $57 / 56$ \\
\hline AG-32b & $60 / 59$ & $57 / 56$ \\
\hline AG-32c* & $43 / 43$ & 43 \\
\hline AG-33 & 70 & $70 / 71$ \\
\hline AG-36 & 70 & 71 \\
\hline AG- 38 & 70 & 72 \\
\hline AG-39 & $55 / 54$ & 48 \\
\hline AG- 41a & $67 / 66$ & $67 / 66$ \\
\hline AG-42 & 70 & $62 / 64$ \\
\hline AG-44 & $66 / 66$ & $52 / 53$ \\
\hline AG 50 & 70 & 71 \\
\hline AG-51 & 70 & 70 \\
\hline $\mathrm{AG}-54 \mathrm{a}$ & $66 / 67$ & $55 / 54$ \\
\hline$A G-54 b^{*}$ & $65 / 64$ & 56 \\
\hline AG-55 & 70 & $66 / 64$ \\
\hline AG-58 & $67 / 66$ & $62 / 65$ \\
\hline AG-60 & 70 & 69 \\
\hline AG-61 & 70 & 71 \\
\hline AG-62 & 70 & 66 \\
\hline AG-63 & $50 / 49$ & $48 / 47$ \\
\hline AG-64 & $61 / 60$ & $57 / 57$ \\
\hline AG- 65 & 70 & $56 / 56$ \\
\hline AG-66 & $68-70$ & 65 \\
\hline AG-68 & 70 & 71 \\
\hline AG-69 & 70 & $61 / 60$ \\
\hline AG70a & 70 & 56 \\
\hline AG70b & 70 & 59 \\
\hline
\end{tabular}

*Disponível para clientes.

considerando as marcas com teores de álcool etílico abaixo de $68,25 \%$ (m/m), o valor mínimo recomendado na RDC no 422 de 16 de setembro de $2020 .^{9}$
Tabela 4. Comparativo entre os teores de álcool em gel encontrado por refratometria e oxirredução com teores de álcool etílico abaixo de $68,25 \%$ $(\mathrm{m} / \mathrm{m})$

\begin{tabular}{ccc}
\hline Marcas & $\begin{array}{c}\text { Teor de álcool etílico } \\
\text { (m/m) por refratometria } \\
\text { bancada (brix/IR) / Ajuste } \\
\text { da curva }\end{array}$ & $\begin{array}{c}\text { Teor de álcool etílico } \\
(\mathrm{m} / \mathrm{m}) \text { por reação de } \\
\text { oxirredução (correção } \\
\text { espectro / média de abs }\end{array}$ \\
\hline AG-8* & $46 / 47$ & \\
AG-12* & $54 / 55$ & $50 / 48$ \\
AG-26a & $65-68$ & $59 / 58$ \\
AG-26b & $63 / 62$ & $56 / 58$ \\
AG-27 & $58 / 57$ & 56 \\
AG-30 & $68-70$ & $58 / 57$ \\
AG-32a & $60 / 59$ & $57 / 56$ \\
AG-32b & $62 / 60$ & $57 / 56$ \\
AG-32c* & $43 / 43$ & 43 \\
AG-39 & $54 / 55$ & $48 / 48$ \\
AG- 41b & 67 & $67 / 66$ \\
AG-42 & 70 & $62 / 64$ \\
AG-44 & $66 / 66$ & $52 / 53$ \\
AG - 54a & $66 / 67$ & $55 / 54$ \\
AG - 54b & $65 / 64$ & 56 \\
AG-55 & 70 & $66 / 64$ \\
AG-58 & $66 / 67$ & $62 / 65$ \\
AG-63 & $50 / 49$ & $47 / 48$ \\
AG-64 & $61 / 60$ & $57 / 57$ \\
AG-65 & 70 & $56 / 56$ \\
AG-66 & $68-70$ & 65 \\
AG-69 & 70 & 59 \\
AG-70a & 70 & - \\
AG-70-b & 70 & \\
AG-70c* & $58(\mathrm{P})$ & 560 \\
\hline
\end{tabular}

*Disponível para clientes. P- Refratômetro portátil.

As duas metodologias aplicadas (refratometria e reação de oxirredução), indicaram que, das 70 marcas avaliadas, 19 delas $(27,1 \%)$ apresentaram teores de álcool etílico, abaixo da faixa recomendada, ${ }^{9}$ portanto, não são efetivas para diminuir a transmissão do SARS-CoV-2.

\section{CONCLUSÕES}

A produção de álcool em gel requer um conhecimento da ciência química a fim de garantir a qualidade do produto, que resultaria a segurança da população. Para a obtenção do álcool em gel no IQ-UFBA, fez uso do produto COMBIZEEL LH $70 \mathrm{MR}$, como espessante, como alternativa, devido à escassez do espessante carbopol. O pH do produto de 6,5-6,7 foi corrigido com baixa demanda de trietanolamina e o álcool em gel chegou à uma boa viscosidade que associada a presença de colágeno hidrolisado resultou em um produto que proporciona uma maior maciez nas mãos. O estudo das 70 marcas de álcool em gel mostrou que a preocupação com a correção do $\mathrm{pH}$ não é seguida pelos fabricantes, foi verificado que $52,85 \%$, das marcas apresentaram $\mathrm{pH}$ acima do recomendado.

A aplicação da refratometria, permite, com certa segurança, a determinação do teor de álcool etílico para diferentes marcas de álcool 
em gel para higienização das mãos e sanitizantes. Como vantagens dessa metodologia é possível enumerar a rapidez na resposta, não geração de resíduos, o custo baixo e a possibilidade de ser feita no local da produção do álcool em gel ou de comercialização, com profissional não especializado.

As análises do teor de álcool etílico por meio da oxidação do álcool mostraram consistentes com os dados obtidos por refratometria. Para 17 marcas $(47,22 \%)$ das 36 marcas avaliadas por meio das duas metodologias têm os valores similares do teor de álcool etílico e dentro do recomendado.

A refratometria e a reação de oxirredução são metodologias complementares para determinar o teor de álcool etílico no álcool em gel. Para uma resposta rápida, a refratometria é mais adequada, porém, a interferência de emolientes pode levar a afirmação não precisa e assim, a busca de uma resposta confiável do teor de etanol requer a aplicação da reação de oxirredução.

A adulteração de desinfetantes para as mãos à base de etanol como ingrediente ativo é uma preocupação cada vez maior no mercado brasileiro, portanto, há necessidade de uma vigilância ativa por parte das autoridades e assim evitar a comercialização de marcas que não mostram atividade antisséptica para uso em meio à pandemia e pós pandemia, como as indicadas neste trabalho.

\section{MATERIAL SUPLEMENTAR}

As Figuras $1 \mathrm{~S}$ à $11 \mathrm{~S}$, o Esquema $1 \mathrm{~S}$ e as Tabelas $1-4 \mathrm{~S}$ contêm as informações que proporcionam melhor compreensão de alguns pontos descritos do trabalho. Elas estão disponíveis em http://quimicanova. sbq.org.br, em arquivo pdf, com acesso livre.

\section{AGRADECIMENTOS}

Eliezer Gomes de Carvalho, pela dedicação na procura de diferentes marcas do álcool em gel. Aos profissionais da área de saúde pela dedicação imensurável no enfrentamento da COVID-19. Dener Pereira dos Santos, pela coleta de algumas marcas de álcool em gel.

\section{REFERÊNCIAS}

1. Berardi, A.; Perinelli, D. R.; Merchantc, H. A.; Bisharat, L.; Basheti, I. A.; Bonacucina, G.; Cespi, M.; Palmieri, G. F.; Int. J. Pharm. 2020, 584 , 119431.
2. Sequinel, R, Lenz, G. F., Lian, F.J., Silva, L. B., Silva, F. R.; Quim. Nova 2020, 43, 679.

3. Kampf, G.; Todt, D.; Pfaender, S.; Steinmann, E. S. J. Hosp. Infect. 2020, 104, 246.

4. Guide to Local Production: WHO-recommended Handrub Formulations, disponível em: https://www.who.int/gpsc/5may/Guide_to_Local_ Production.pdf, acessada em setembro 2021.

5. Suchomel, M.; Kundi, M.; Pittet, D.; Weinlich, M.; Rotter, M. L.; Am. J. Infect. Control 2012, 40, 328.

6. Wilkinson, M.A.C.; Ormandy, K.; Bradley, C.R.; Fraise, A.P.; Hines, J.; Dose. J. Hosp. Infect. 2017. 95, 175.

7. BRASIL, Ministério da Saúde, Agência Nacional de Vigilância Sanitária, Formulário nacional da farmacopeia brasileira, $2^{\mathrm{a}}$ ed., Anvisa: Brasília, 2012, disponível em https://www.gov.br/anvisa/pt-br/ assuntos/farmacopeia/formulario-nacional/arquivos/8065json-file-1, acessada em setembro 2021.

8. BRASIL, Ministério da Saúde, Agência Nacional de Vigilância Sanitária, Orientações Gerais para Produção de Formulações Antissépticas Alcoólicas, 24 de março de 2020, disponível em https:// www.gov.br/anvisa/pt-br/arquivos-noticias-anvisa/743json-file-1, acessada em setembro 2021.

9. BRASIL, Ministério da Saúde, Agência Nacional de Vigilância Sanitária, Resolução da Diretoria Colegiada $(R D C) N^{o}$. 422, Diário Oficial da União (DOU), 17/09/2020. Edição:179, seção 1. Página:133.

10. BRASIL, Ministério da Saúde, Agência Nacional de Vigilância Sanitária, Resolução da Diretoria Colegiada (RDC) No. 350, Diário Oficial da União (DOU), 20/03/2020. Edição: 55, seção 1. Página:154.

11. Fonseca Jr., F. S.; Brito, L. R.; Pimentel M. F.; Leal, L. B.; J. Braz. Chem. Soc. 2020, 31, 1759.

12. Pasquini, C.; Hespanhol, M. C.; Cruz, K. A. M. L.; Pereira, A. F.; Microchem. J. 2020, 159, 105421.

13. Shriver, D.; Atkins, P.; Química inorgânica, $4^{\text {th }}$ ed., Bookman: Porto Alegre, 2008.

14. Singh, S.; Physica Scripta 2002, 65, 167.

15. Galvão, A. C; Robazza, W da Silva; Da Silva, I. R; Almeida, C. M.; Ciência e Natura 2015, 37, 641.

16. Martins, A.; Laurent, R.; Aznarez, S. B.; Postigo, M. A.; Eclética Química 2000, 25, 161. 